\title{
OC-055 THE ROLE OF THE SPINAL CORD IN BOWEL DYSFUNCTION SECONDARY TO MULTIPLE SCLEROSIS: A COMPARISON WITH SUPRA-CONAL SPINAL CORD INJURY
}

doi:10.1136/gut.2011.239301.55

G Preziosi, ${ }^{*}$ A Roy, P Boulos, A Emmanuel Gl Physiology Unit, University College London Hospital, London, UK

Introduction Bowel dysfunction in multiple sclerosis (MS) and spinal cord injury (SCI) is common, affecting up to $2 / 3$ of patients, with constipation and incontinence often co-existing. In MS we have shown that spinal cord involvement by the disease predicts bowel dysfunction. Spinal disease burden is easily measured clinically by EDSS (expanded disability status scale, $0-4.5=$ mild disability, $5-10=$ high disability). In supraconal-SCI the autonomic dysfunction underlying bowel symptoms causes increased rectal compliance (RC). We hypothesised that spinal cord involvement by MS is responsible for the autonomic dysfunction affecting the rectum, hence compared RC between MS, supraconal-SCI patients and normal controls.

Methods Forty-five MS patients with bowel symptoms were divided in two groups according to EDSS: MS-A (EDSS $<5$, $\mathrm{n}=25)$ and MS-B (EDSS $>5, \mathrm{n}=20)$. Rectal compliance and Wexner constipation and incontinence scores were compared with 19 Supraconal-SCI patients and 25 normal controls. Age, gender and parity were well-matched between groups.

Results Rectal compliance ( $\mathrm{ml} / \mathrm{mmHg}$ ) post-hoc analysis in table 1 .

Table 1 OC-055 RC in the 4 groups

\begin{tabular}{ll} 
MS-A $(E D S S<5,10.5 \pm 4.3)$ vs Normal $(11 \pm 3)$ & $\mathrm{p}=0.981$ \\
MS-A $(E D S S<5,10.5 \pm 4.3)$ vs MS-B $(E D S S>5,15.4 \pm 5.6)$ & $\mathrm{p}=0.005$ \\
MS-A $(E D S S<5,10.5 \pm 4.3)$ vs Spinal $(18 \pm 5.8)$ & $\mathrm{p}<0.001$ \\
MS-B $(E D S S>5,15.4 \pm 5.6)$ vs Normal $(11 \pm 3)$ & $\mathrm{p}=0.016$ \\
MS-B $(E D S S>5,15.4 \pm 5.6)$ vs Spinal $(18 \pm 5.8)$ & $\mathrm{p}=0.303$ \\
Spinal $(18 \pm 5.8)$ vs Normal(11 \pm 3$)$ & $\mathrm{p}<0.001$ \\
\hline
\end{tabular}


Wexner-Incontinence:

MS-A $(6.12 \pm 4.72)$ vs MS-B $(9.8 \pm 6.4) p=0.96$

MS-A $(6.12 \pm 4.72)$ vs Spinal $(10.8 \pm 5.3) p=0.033$

MS-B $(9.8 \pm 6.4)$ vs Spinal $(10.8 \pm 5.3) p=0.883$.

Wexner-Constipation:

MS-A (10.8 \pm 5.3$)$ vs MS-B $(11.3 \pm 4.3) p=0.951$

MS-A $(10.8 \pm 5.3)$ vs Spinal $(15.4 \pm 5.8) p=0.025$

MS-B $(11.3 \pm 4.3)$ vs Spinal $(15.4 \pm 5.8) p=0.065$.

In the MS group there was a strong relationship between EDSS and $\mathrm{RC}(\mathrm{r}=0.438, \mathrm{p}=0.003 ; \beta=0.487, \mathrm{p}=0.001)$.

\section{Conclusion}

Rectal compliance is increased similarly in both MS patients with high disability and supraconal-SCI patients, suggesting that similar autonomic dysfunction underlies bowel symptoms in both groups. Bowel dysfunction in MS is multifactorial, but spinal cord involvement by MS seems critical to development of both constipation and incontinence.

Competing interests None.

Keywords motility, multiple sclerosis, Neurological bowel dysfunction, rectal compliance, spinal cord injury. 